\title{
Osseous Stress Reaction in a Rower Diagnosed with Positron Emission To- mography (P.E.T.): A Case Report
}

\author{
Curtis W. Slipman, MD, Rajeev K. Patel, MD, Edward J. Vresilovic, MD, PhD, Peter Brautigam, MD, \\ Alexander Mathies, MD, Lars E. Adam, PhD, David Lenrow, MD, Atul L. Bhat, MD, Zacharia, Isaac, \\ MD, and Abass Alavi, MD
}

Back injury is one of the most frequently encountered injuries in the collegiate rower. The differential diagnosis of back pain in the competitive rower includes muscle strain, ligament/tendon injury, stress reaction, stress fracture, and a tear in the annulus fibrosis.

Endurance sports, such as rowing, have an increased frequency of stress injury The diagnosis of stress reaction cannot be made with plain radiographs. Many studies have firmly established the efficacy of single photon emission computed tomography (SPECT) bone scans and magnetic

Back injury is one of the most frequently encountered injuries to the collegiate rower (1). The differential diagnosis of back pain in the competitive rower includes muscle strain, ligament/tendon injury, stress reaction, stress fracture, and a tear in the annulus fibrosis. Endurance sports, such as rowing, have an increased frequency of stress injury (2). In 1985, Holden and Jackson reported a series of rib fractures in elite female rowers (3). Subsequently, during a review of rowing injuries, Josea and Boland reported eight cases of rib-stress injury diagnosed by bone scan (4).

The back produces much of the power required to complete a rowing stroke. Myoelectric and kinematic analysis of the lumbar spine during rowing reveals that the peak stress forces at L4 are approximately 848 Newtons (N) in men and $717 \mathrm{~N}$ in women rowers. The average peak compressive loads range from 5000 to $6000 \mathrm{~N}$ in women and

From the departments of Rehabilitation Medicine, Radiology, and Orthopedic Surgery, University of Pennsylvania, Philadelphia, Pennsylvania and Department of Orthopedics, University of Rochester Medical Center, Rochester, New York. Address correspondence: Curtis W. Slipman, MD, Director, The Penn Spine Center, Ground Floor White Bldg., 3400 Spruce Street, Philadelphia, PA 19104. Email: slipman@mail.med.upenn.edu resonance imaging in establishing the diagnosis of a stress reaction

We present a case of a collegiate rower with mid back pain secondary to a stress reaction of the endplates of the costotransverse articulation at the T8 level diagnosed by a positive positron emission tomogram study in the setting of a negative SPECT scan.

Keywords: Back pain, stress fracture, PET scan, SPECT scan

men rowers, respectively, approximating seven times the body weight during the drive phase. These high forces put the lumbar spine at risk during vigorous rowing activity, causing the spine to endure repetitive mechanical stress (1). Biomechanical studies suggest that the highest bending stresses occur at the posterolateral section of the rib (5). To transfer the force generated by the legs and trunk into the arms, and subsequently to the oar, the scapulothoracic muscles, especially the serratus anterior, must contract maximally (1). This produces a bellowstype effect on the rib cage, which can result in a stress fracture (1). Repetitive microtrauma to the chest wall and scapulothoracic area can lead to painfully unstable subluxating ribs, scapulothoracic articulation fibrosis, or stress fracture of the ribs, which have all been well documented in rowers $(3,6,7)$.

Stress injuries can be viewed as a spectrum of stress reaction to stress fracture (8). The diagnosis of stress reaction cannot be made with plain radiographs (9). Many studies have firmly established that single photon emission computed tomography (SPECT) bone scans are the diagnostic test of choice in establishing the diagnosis of a stress reaction (10-14). Magnetic resonance imaging (MRI) is a highly sensitive test for the diagnosis of stress injury to bone (15). Magnetic resonance imaging is similar to SPECT in that it allows for depiction of abnormalities several weeks prior to the development of radiographic alter- 
ations. A combination of T1-weighted sequences, which optimizes anatomic detail, and a sequence that depicts bone "edema" are required for the assessment of stress injuries (15). Short-time inversion recovery sequences are the most commonly used edema-sensitive images and typically incorporate fat suppression techniques to further enhance contrast (16).

In 1962, Blau et al introduced the concept of positron emitted $\left[{ }^{18} \mathrm{~F}\right]$ fluoride ion for bone scanning $(17) . \quad\left[{ }^{18} \mathrm{~F}\right]$ Fluoride ion is extracted from plasma in proportion to bone perfusion (18-22). The efficiency of any radiotracer extraction is affected by the permeability of the capillary membrane that separates the vascular component from the tissue compartment (23). Fluoride ion can more easily cross the capillary membrane compared to the larger complex molecules of ${ }^{99 m}$ Tc-labeled phosphate agents (18). The first-pass extraction of fluoride ion in normal bone is nearly $100 \%$ (21), and increased uptake may be seen secondary to regional increases in blood flow. For comparison, ${ }^{99 \mathrm{~m}} \mathrm{Tc}$ diphosphonate compounds have a first-pass extraction efficiency of approximately $60 \%$ in the presence of normal bone capillary permeability (18). The biological characteristics of fluoride ion follow a more clearly defined physiologic process, allowing absolute quantitative evaluations of the skeletal system when combined with positron emission tomography technology $(24,25)$. Another useful feature of the $\left[{ }^{18} \mathrm{~F}\right]$ fluoride ion is excellent bone-toplasma ratios at the time if imaging, which can usually be initiated 40 to 60 minutes after isotope injection, allowing the entire patient visit to be completed in less than 2 hours (23).

Positron emission tomography is an imaging modality that provides regional as well as global information about physiology, chemistry, and metabolism within various body organs (26). The PET scanner itself consists of large positron-sensitive sodium iodide crystal detectors individually analyzed by 180 to 240 photomultiplier tubes. Images are photographed by cameras having a 4.0- to 5.5millimeter resolution and subsequently constructed by Sun SPARC station computers and array processors. Positron emission tomography scanning utilizes intravenously (IV) injected radioactively labeled glucose $\left[{ }^{18} \mathrm{~F}-\mathrm{FDG}\right]$ to identify areas of increased tissue metabolism. Specifically, PET ascertains physiology by demonstrating areas of increased glucose metabolism, oxygen utilization, or neurotransmitter release. When attempting to delineate bone pathology, PET identifies areas of increased osteoblastic and osteoclastic activity, produces tomographic images that have better resolution than SPECT, and is more quantita- tively and anatomically precise (27). The reason for this disparity in image quality is the ability of PET to more accurately correct for tissue photon attenuation (27).

This report describes a collegiate rower who complained of mid back pain secondary to a stress reaction of the endplates of the costotransverse articulation at the T8 level diagnosed by a positive PET study in the setting of a negative SPECT scan.

\section{CASE REPORT}

A 22-year-old male collegiate rower presented to our spine center stating a chief complaint of mid-back pain. His symptoms were located on the right side, just off midline, below the inferior aspect of the spine of the scapula, and radiated laterally to the right. His pain was initially felt during the drive phase of a rowing stroke beginning 4 months prior to presentation. The intensity of the pain was modest at rest, 50 out of 100 on the visual analogue scale (VAS), but excruciating, 90 out of 100 on the VAS scale, during rowing. His symptoms consisted of a stabbing and aching quality and had been intensifying over the previous 2 weeks prior to presentation. The pain had not affected his sleeping pattern; however, he had to progressively decrease his rowing to the point that he stopped rowing completely approximately 1 week prior to presentation.

Rowing exacerbated the patients' symptoms the most, but sitting for longer than 1 hour also provoked his pain. Advil@, electrical stimulation, and rest provided partial and temporary reduction of symptoms. The patient had initiated a nonspecific physical therapy program just prior to presentation; however, no other treatment had been instituted. The patient had no prior medical or surgical history. His review of systems was noncontributory. There was no significant family medical history. He had no known drug allergies. He was an unmarried university student who consumed one to three alcoholic beverages per week and denied any tobacco or illicit drug use. He was independent, with all activities of daily living and everyday community activities. On physical examination, the patient was a well-developed, young Caucasian man who stood six feet one-inch tall and weighed 190 pounds, with normal vital signs. His skin was without scar, rashes, or ulcers. There was no lymphadenopathy. Gross inspection for deformity was unremarkable. Palpation over the midback inferior to the scapula did not elicit any complaints of pain or tenderness. Girth of the mid-quad and mid-calf were symmetrical. Dorsalis pedis pulses were 
graded $2+$ and strong. Joints in the lower extremities were without effusion and crepitus. Discogenic stress maneuvers were not pain provoking. Sacroiliac stress maneuvers were not pain provoking bilaterally. The patient was able to heel walk, toe walk, and tandem walk without pain or difficulty. Sensation was intact to a pin between T4 and T12 bilaterally. Deep tendon reflexes were graded 2+ and symmetrical at the biceps, brachioradialis, triceps, patella and Achilles bilaterally. Long tract signs were negative bilaterally. Coordination, orientation, mood and affect were normal. Manual muscle testing was graded 5 out of 5 and full in the upper and lower extremities bilaterally. Lumbar flexion was achieved with a long finger to floor distance of $0 \mathrm{~cm}$ without discomfort. Lumbar extension was achieved to 50 degrees; however, the patient's usual pain was provoked. Lumbar side bending was achieved to within normal limits without difficulty. Range of motion of the hips, knees, and ankles was within normal limits. An MRI of the thoracic spine, dated approximately 1 month prior to presentation, demonstrated no pathology. There was normal alignment, well-hydrated intervertebral discs, no central or foraminal stenosis, and no disc herniation.

Our initial clinical suspicion was that symptoms were caused by a stress reaction of the posterior elements of the thoracic spine. Bone SPECT scan was acquired 3 hours after IV injection of $750 \mathrm{MBq}{ }^{99 \mathrm{~m} T c-M D P}$ using a dual-

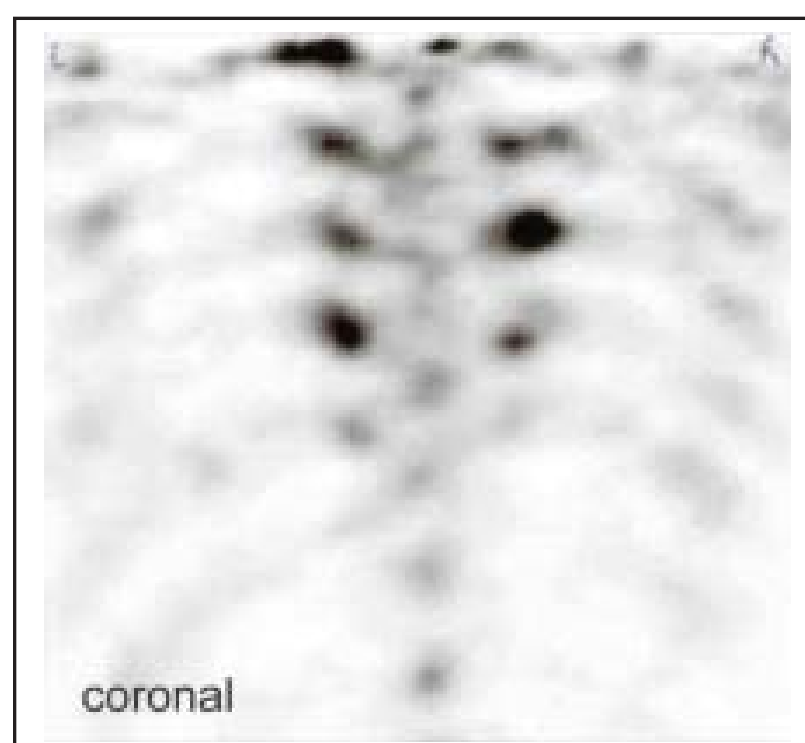

Fig. 1a. Transverse view at the T9 level demonstrating high uptake on the right costo-transverse articulation. headed gamma camera (Picker Prism ${ }^{\circledR}$ 2000). This scan failed to demonstrate abnormal bone metabolism. Subsequently, a PET scan was performed using a dedicated PET scanner (C-PET®, ADAC UGM). Approximately 110 minutes after IV injection of $142 \mathrm{MBq}\left[{ }^{18} \mathrm{~F}\right]$-sodium fluoride (1.64 MBq/kg BW), three emission scans of 6 minutes each, covering $51.2 \mathrm{~cm}$ axial FOV, were acquired. Interleaved postinjection singles transmission scans of 1-minute duration were acquired using a $\left[{ }^{137} \mathrm{Cs}\right]$ point source. Image reconstruction employed an iterative algorithm (RAMLA), including corrections for scatter and decay. The transverse image of the thoracic spine (Fig. 1a) reveals several foci of moderate-to-high tracer uptake, predominantly at the costotransverse articulations of T7 to T10 bilaterally, consistent with a stress-induced alteration in the bone metabolism. Fig. 1b displays the transverse image of the patient's scan at the level of T9. The normal tracer distribution of $\left[{ }^{18} \mathrm{~F}\right]$-sodium fluoride, using a comparable PET acquisition in a healthy 19 year-old man without symptoms, is shown in Figs. $2 \mathrm{a}$ and $2 \mathrm{~b}$.

\section{DISCUSSION}

Stress fractures occur as a result of bones being exposed to repeated cyclic loading that eventually exceeds its elastic resistance $(28,29)$. There are two types of stress fractures. Fatigue fractures, such as tibial stress fractures in long-distance runners, occur when abnormal stress is ap-

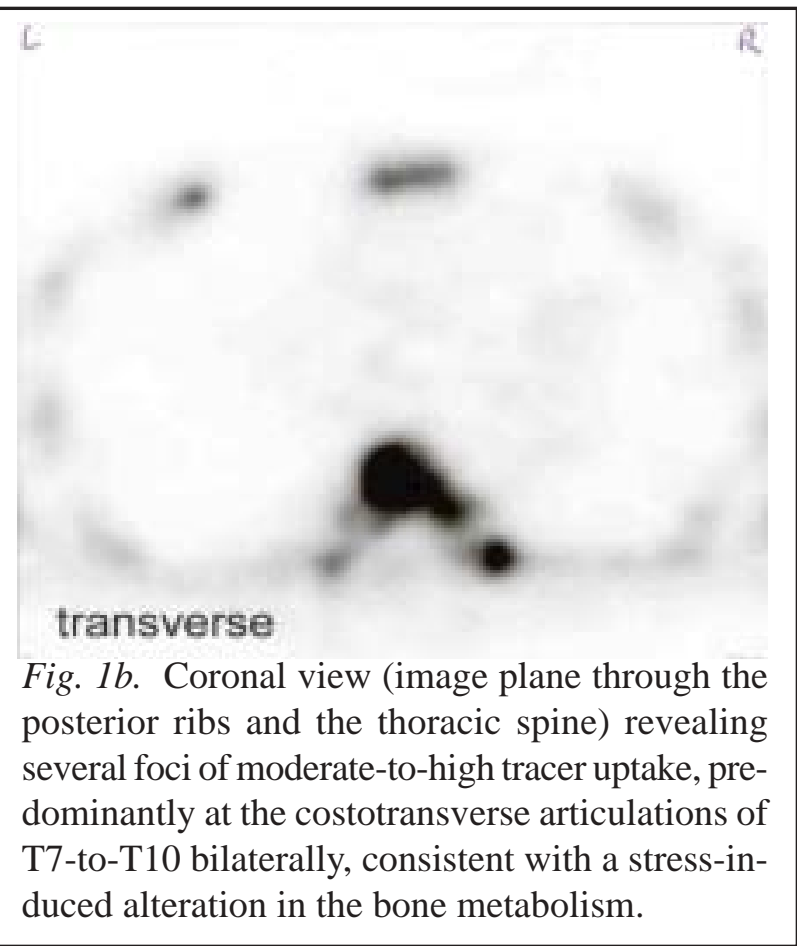




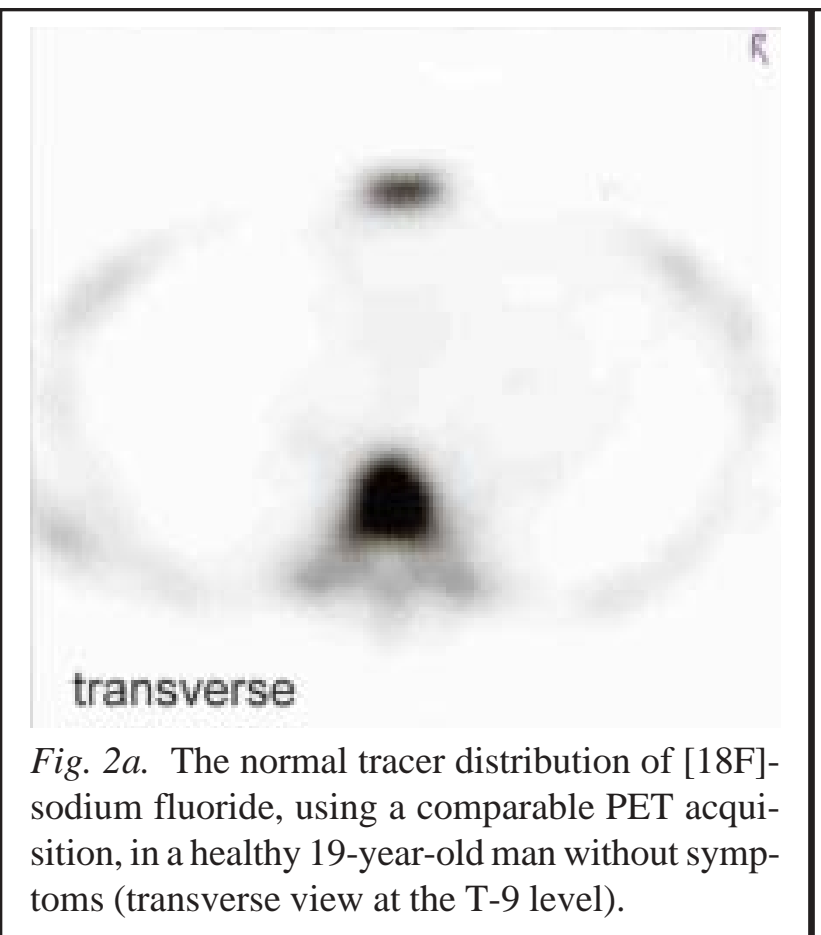

plied to normal bone $(28,29)$. Insufficiency fractures occur when normal forces are applied to abnormal or weakened bone, such as vertebral compression fractures in osteoporotic patients $(28,29)$.

In 1855, Breithraupt, a Prussian military surgeon, originally described stress injury to bone in military soldiers (30). This entity was initially visualized via roenterography approximately four decades later (31). As comprehension of the pathophysiology of overuse injury has emerged, and progress in radionuclide imaging has occurred, a model of stress injury to bone has been proposed. This paradigm suggests that stress injury to bone occurs on a continuum, ranging from normal bone remodeling/repair to stress reaction to frank cortical fractures (32). Currently, terms such as bone strain (33) and stress reaction (34) are used to reflect the early pathological response of bone to repetitive mechanical loading. If the inciting external stress continues, the stress response may progress to trabecular or cortical disruption and become a stress fracture.

It is universally accepted that bone is a dynamic tissue that undergoes continuous remodeling in response to the demands placed upon it. Under normal conditions the rate of bone formation equals that of bone resorption. When cyclic mechanical forces (stress) are applied to bone, this homeostatic equation may be altered, leading to a stress injury (35). Following the application of a sudden pulse

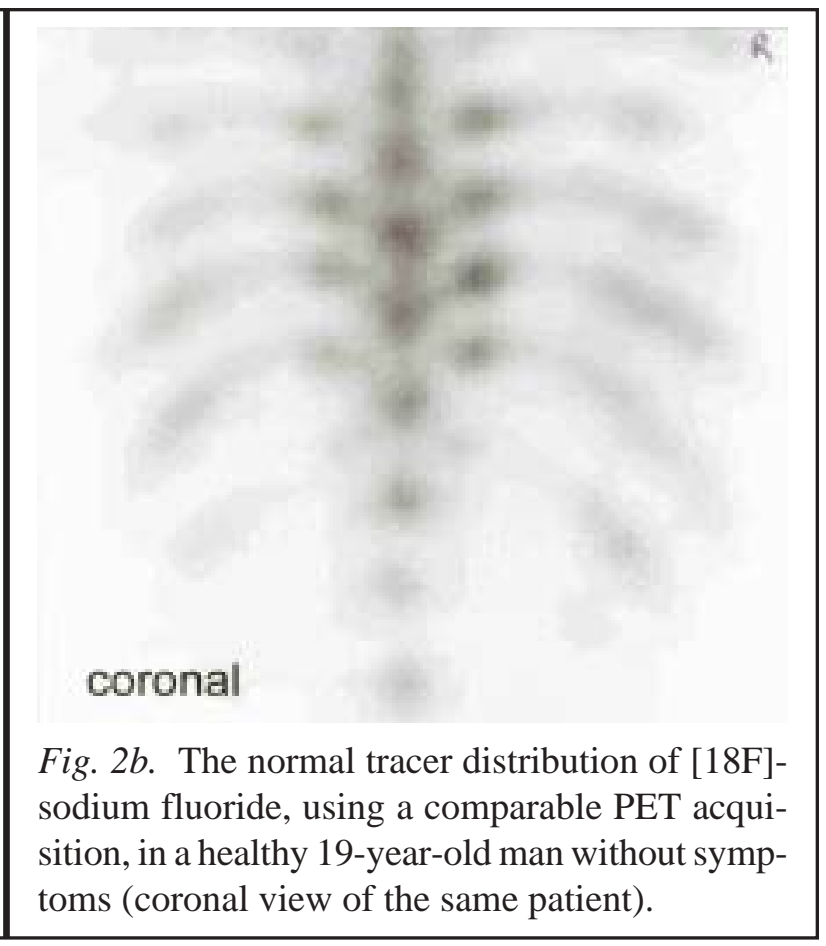

of increased stress upon bone, there is an initial osteoclastic response that may weaken bone. Osteoblastic activity subsequently increases in an attempt to balance bone loss and, thereby, strengthen the bone. If the repetitive musculoskeletal demands persist without sufficient time to allow for restitution of a homeostatic osseous balance, the rate of healing may be overwhelmed, leading to a stress reaction or fracture.

The cyclic mechanical forces that regulate bone remodeling exist mainly in two forms: compressive and tensile. The compressive forces are resisted by the mineral component of bone, whereas the tensile forces are resisted by the collagen component. This complex interaction of transmitted forces upon the organic/mineral matrix of bone and the resultant adaptive remodeling is expressed in Wolff's law. The bony adaptation is a function of the number of loading cycles, cycle frequency, amount of strain, strain rate, and strain duration per cycle (36). Bone responds to excess strain by osteonal remodeling (ie resorption of circumferential lamellar bone and replacement by dense osteonal bone). Whether adaptation results in strengthening or weakening of the tissue is dependent on a multitude of factors: metabolic state, present level of fitness, biomechanical changes, menstrual patterns, age, sex, and ethnicity (36).

In 1963, Johnson et al (37) described the histogenesis of 
stress reactions. During the first week there was active osteoclastic resorption of the cortex; but decalcification, microfracture, microcallus, and osteocyte death were not apparent. During the second week, endosteal (and occasional periosteal) callus formation was present. Johnson found that, if the inciting activity was discontinued at this time, no actual fracture occurred. On the other hand, if the inciting activity was continued, a thin crack appeared in the cortex. Resorption was complete at the end of 3 weeks, and callus was maximal at 6 weeks. When bone is stressed, there is a gradual and progressive resorption of circumferential lamellar bone and its subsequent replacement by dense osteonal bone. This period of remodeling is characterized by local hyperemia, edema, and osteoclastic activity. As a consequence of this process, a vulnerable period exists following a stressful occurrence in which the cortical bone is less capable of withstanding further stress and in which foci of osseous resorption may be transformed into sites of microfracture. Stress events in bone are more likely to occur when there has been an increase in the strength of the acting muscle over a relatively short time as the concomitant increase in strength of bone lags behind that of muscle. The stress fracture begins as a small cortical crack that can progress as the stress continues $(1,4,5)$. This progression is characterized by the appearance of subcortical infarction in front of the main crack in the bone. If the stress is eliminated, the sequence is interrupted or slowed so that new bone formation can "catch up" with the increased demand, and a state of increased bone strength is achieved. Rest interrupts the process for osteoblastic activity to outpace osteoclastic activity, thereby allowing for periosteal or endosteal healing (38).

A variety of theories have been proposed to explain the biomechanics and pathophysiology of the stress response. The classical and perhaps oversimplified explanation is that a change in the volume or intensity of mechanical stress applied to bone overwhelms the bones' remodeling process, described as Wolff's law (39-41). Another theory is that physical exercise leads to muscle fatigue, thereby altering movement patterns and distributions of stress, with resultant excessive concentration of force being transmitted to focal sites in the underlying bone $(42,43)$. A third proposal is that repetitive mechanical loading results in increased muscle activity, with secondary concentration of excess force at the sites of origin or insertion of the muscle on the bone (44). Carter and Caler (45) suggest that bone remodeling occurs as a result of the piezoelectric phenomena. This suggests that tension forces create an electropositivity that results in bone resorption by initiating osteoclastic activity. Weakened bone is therefore created, and is susceptible to injury or fracture. Alternatively, compression forces develop an electronegative field that induces bone deposition by osteoblastic activity and strengthens bone. Carter has shown that most cortical stressors are tension or torsion in nature, and tend to result in microfractures along a cement line (43). Histologically, small cracks can be seen at the cement lines of the haversian canals (46). Frost (47) proposed a new theory of bone biology to help understand the skeletal adaptations that occur with mechanical usage. This paradigm is based on a "mechanostat theory" to explain the structural and density changes of bone that ensue when bone is repeatedly stressed by its mechanical environment $(47,48)$. The mechanostat theory is based on two main premises. First, there exists a minimum strain threshold for modeling (MESm) and another minimum strain threshold for remodeling (MESr). These two thresholds are viewed as "set points," between which most normal activity occurs (within the physiologic loading zone). Second is that a "controller" of bone biology (the mechanostat) senses bone strain induced by mechanical usage and compares it to the MESm and MESr thresholds and activates an adaptive cellular response. The mechanostat theory, therefore, helps to bridge the gap between bone adaptations to mechanical stress (exercise) and environmental factors.

\section{CONCLUSION}

This is the report of a case in which PET scan diagnosed a stress reaction when other radiological studies were inconclusive. Positron emission tomography scan may be more sensitive than either SPECT or MRI in diagnosing an early stress reaction in bone; however, further study is required comparing these diagnostic studies directly before any definitive statement can be made.

\section{REFERENCES}

1. Bland AL, Hosea TM. Rowing and sculling and the older athlete. Clin Sports Med 1991; 10: 245-256.

2. Orava S, Jromakka E, Hulkko A. Stress fractures in young athletes. Arch Orthop Trauma Surg 1981; 98:271.

3. Holden DL, Jackson DW. Stress fractures of the ribs in female rowers. Am J Sports Med 1985; 13:342-5.

4. Josea TM, Boland AL, McCarthy K et al. Rowing Injuries. Post Graduate Advances in Sports Medicine 1989; 3:9.

5. Derbes VJ, Harran T. Rib fractures from muscular effort with particular reference to cough. Surgery 1954; 35: 294-321.

6. Ormandy L. Scapulocostal syndrome. Va Med 1994; 
Q 12:105-108.

7. Thomas PL. Thoracic back pain in rowers and butterfly swimmers-costovertebral subluxation. Br J Sports Med 1988; 22:81.

8. Knapp TP, Garrett WE. Stress fractures: General concepts. Clin Sports Med 1997; 16: 339-355.

9. Gerbino PG II, Micheli LJ. Back injuries in the young athlete. Clin Sports Med 1995; 14:3 571-590.

10. Bellah RD, Summerville DA, Treves ST et al. Low back pain in adolescent athletes: Detection of stress injury to the pars interarticularis with SPECT. Radiology 1991; 180: 609-612.

11. Collier BD, Jognson RP, Carrera GF et al. Painful spondylolysis or spondylolisthesis studied by radiography and single photon emission computed tomography. Radiology 1985; 154: 207-211.

12. Papanicolaou N, Wilkinson RH, Emans JB et al. Bone scintigraphy and radiography in young athletes with low back pain. AJR 1985; 145: 1039-1044.

13. Pennell RG, Maurer AH, Bonakdarpour A. Stress injuries of the pars interarticularis: Radiologic classification and indications for scinitigraphy. AJR 1985; 145: 763-766.

14. Rosen PR, Micheli LJ, Treves S. Early scinitgraphic diagnosis of bone stress and fractures in athletic adolescents. Pediatrics 1982; 70: 11-5.

15. Deutsch AL, Coel MN, Mink JH. Imaging of stress injuries to bone. Clin Sports Med 1997; 16:2 275-290.

16. Meyers SP, Wiener SN. Magnetic resonance imaging features of fractures using the short tau inversion (STIR) sequence: Correlation with radiographic findings. Skeletal Radiol 1991;20: 4999-5007.

17. Blau M, Nagler W, Bender MA. Fluorine-18: A new isotope for bone scanning. J Nucl Med 1962; 3:332334.

18. Garnett ES, Bowen BM, Coates Get al. An analysis of factors which influence the local accumulation of boneseeking radiopharmaceuticals. Invest Radiol 1975; 10: 564-568.

19. Green JR, Reeve J, Tellez Met al. Skeletal blood flow in metabolic disorders of the skeleton. Bone 1987; 8: 293-297.

20. Weber DA, Greenberg EJ, Dimich A et al. Kinetics of radionuclides used for bone studies. J Nucl Med 1969; 10: 8-17.

21. Wootton R, Dore C. The single-passage extraction of ${ }^{18} \mathrm{~F}$ in rabbit bone. Clin Phys Physiol Meas 1986; 7: 333-343.

22. Van Dyke D, Anger HO, Yano Y et al. Bone blood flow shown with F-18 and the positron camera. Am J Physiol 1965; 209: 65-70.

23. Akerhalt RE, Blau M, Bakshi S et al. A comparative study of three $99 \mathrm{mTc}$-labeled phosphorus compounds and ${ }^{18} \mathrm{~F}$ - fluoride for skeletal imaging. $\mathrm{J} \mathrm{Nucl} \mathrm{Med}$ 1974; 15: 1153-7.

24. Hawkins RA, Choi Y, Huang SC et al. Evaluation of the skeletal kinetics of fluorine-18-fluoride ion with PET. J Nucl Med 1992; 33: 633-642.

25. Nahmias C, Cockshott WP, Belbeck LW et al. Measurement of absolute bone blood flow by positron emission tomography. Skeletal Radiol 1986; 15: 198200.

26. Kuhl DE, Wagner HN, Alavi A et al. Positron emission tomography: Clinical status in the United States in 1987. J Nucl Med 1988; 29: 1136-1143.

27. Hoh CK, Hawkins RA, Dahlbom M et al. Whole body skeletal imaging with $\left[{ }^{18} \mathrm{~F}\right]$ Fluoride ion and PET. $J$ Computed Assisted Tomography 1993; 17: 34-41.

28. Cooper KL, Beabout JW, Swee RG. Insufficiency fractures of the sacrum. Radiology 1985; 156: 15-20.

29. Renner JB. Pelvic insufficiency fractures. Arthritis Rheum 1990; 33: 426

30. Breithaupt MD. Zur pathologie des menschlichen fuses. Med Zeitung 1855;24:169.

31. Stechow AW. Fussoderm and roentgenstrahlen. Detsh Mil Aerztl Zeitg 1897;26: 465.

32. Nattiv A, Armsey TD Jr. Stress injury to bone in the female athlete. Clin Sports Med 1997; 16:2 197-224.

33. Matheson GO, Clement DM, McKenzie DC et al. Stress Fractures in Athletes: A study of 320 cases. Am J Sports Med 1987;15:46-58.

34. Jones BH, Harris JM, Vinh TN et al. Exercise-induced stress fractures and stress reaction of bone: Epidemiology, etiology, and classification. Exerc Sport Sci Rev 1989; 17:379-472.

35. Arendt EA, Griffiths HJ. The use of MR imaging in the assessment and clinical management of stress reactions of bone in high performance athletes. Clin Sports Med 1997; 16: 291-306.

36. Sterling JC, Edelstein DW, Calvo RD et al. Stress fractures in the athlete: Diagnosis and management. Sports Med 1992; 14:336-346.

37. Johnson LC, Stradford HT, Gets RW et al. Histogenesis of stress fractures abstract. J Bone Joint Surg 1963; 45A: 1542.

38. Coady CM, Micheli LJ. Stress fractures in the pediatric athlete. Clin Sports Med 1997; 16:2 225-238.

39. Chamay A, Tschantz P. Mechanical influences in bone remodeling: Experimental research on Wolff's law. $J$ Biomechanics 1972; 5:173.

40. Hershman E and Mailly T. Stress fractures. Clin Sports Med 1990; 9:183-214.

41. Markey K. Stress fractures. Clin Sports Med 1987; 6: 405 .

42. Baker J, Franker VH. Fatigue fractures: Biomechanical considerations. J Bone Joint Surg 1972; 54A: 13456.

43. Daffner RH, Pavlow H. Stress fractures: Current concepts. Am J Roentgenol 1992; 159:245.

44. Stanitski CL, McMaster JH, Scranton PE. On the nature of stress fractures. Am J Sports Med 1988; 16: 378 . 
45. Carter DR, Caler WE. A cumulative damage model for bone fracture. J Ortho Res 1985; 3:84-90.

46. Marder R. Stress fractures. In Chapman, M (ed): $O p$ erative Orthopaedics, ed 2. Philadelphia, J.B. Lippincott, 1993.
47. Frost HM. A new direction for osteoporosis research: A review and proposal. Bone 1991; 12: 429-38.

Grimston SK. An application of mechanostat theory to research design: A theoretical model. Med Sci Sports Exerc 1993; 25: 1293-1297. 